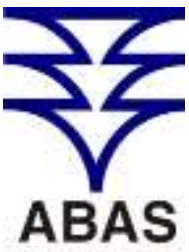


www.abas.org

\section{A UTILIZAÇÃO DA ANÁLISE DE VARIÂNCIA (ANOVA) \\ NA DISTINÇÃO DE AQUÍFEROS SEDIMENTARES NA REGIÃO DO RECÔNCAVO NORTE, ESTADO DA BAHIA}

USE OF VARIANCE ANALYSIS (ANOVA) IN THE DISTINCTION OF SEDIMENTARY AQUIFERS IN THE RECONNCAVO NORTE REGION-BAHIA

\author{
Sérgio Augusto de Morais Nascimento ${ }^{1}$; Luiz Rogério Bastos Leal ${ }^{2}$; \\ Carlos Gleidson Campos da Purificação ${ }^{3}$
}

Artigo recebido em: 22/07/2016 e aceito para publicação em: 02/10/2016.

DOI: http://dx.doi.org/10.14295/ras.v30i3.28654

\begin{abstract}
Resumo: Esse trabalho teve como objetivo estudar e comparar a existência de similaridade hidrogeoquímica entre as Formações Barreiras, Marizal e São Sebastião situadas na região do Recôncavo Norte, estado da Bahia. As informações foram obtidas a partir do banco de dados da Companhia de Pesquisa e Recursos Minerais (CPRM) e dos arquivos da Companhia de Engenharia Ambiental e Recursos Hídricos da Bahia (CERB). Os resultados mostraram que as águas das três Formações são predominantemente de natureza cloretada-sódica, apresentando relações iônicas do tipo $\mathrm{rCl}>\mathrm{rHCO}_{3}>\mathrm{rSO}_{4}$ e, secundariamente, $\mathrm{rHCO}_{3}>\mathrm{rCl}>\mathrm{rSO} \mathrm{SO}_{4}$, sendo essa última relação mais comum na Formação São Sebastião a qual apresenta também uma frequência maior de águas bicarbonatadas-sódicas. Os testes comparativos com a análise de variância (ANOVA) apontaram para uma diferenciação entre as citadas Formações somente quanto à presença de sódio e potássio. No caso do sódio, existe uma diferença entre as Formações Barreiras e São Sebastião e, no caso do potássio, existem diferenças entre as Formações Barreiras e Marizal, Marizal e São Sebastião, respectivamente. A explicação para esse fenômeno está ligada com as trocas de cátions regulada pelo $\mathrm{pH}$, principalmente entre o sódio e o cálcio, em função da maior ou menor presença do bicarbonato. Este, por sua vez, esteve fortemente correlacionado ao sódio (r=0,70) na Formação São Sebastião. Finalmente, o modelo utilizado nesse trabalho, mostrou que existe mais evidência sobre a troca iônica entre os níveis argilosos da Formação São Sebastião com a água subterrânea do que com relação às outras Formações estudadas o que era esperado tendo em vista tratar-se de um aquífero multiconfinado constituído por vários níveis argilosos.
\end{abstract}

Palavras-chave: Hidrogeoquímica. Água subterrânea. Estudo comparativo.

Abstract: The purpose of this report is to compare the existence of hydrogeochemical similarity between the Barreiras, Marizal and São Sebastião Formations located in the Recôncavo Norte region of the State of Bahia. Geochemical data was obtained from the databases of the Companhia de Pesquisa e Recursos Minerais (CPRM) and the Companhia de Engenharia Ambiental e Recursos Hídricos da Bahia (CERB). The results showed that the waters of the three Formations are predominantly of a chlorinated-sodic nature, with primarily $\mathrm{rCl}^{>} \mathrm{rHCO}_{3}>$ $\mathrm{rSO}_{4}$ and secondarily $\mathrm{rHCO}_{3}>\mathrm{rCl}>\mathrm{rSO}_{4}$, ionic ratios the latter of which was the most common relationship in the São Sebastião Formation, where there is a higher frequency of sodium bicarbonate composition. Comparative ANOVA tests indicated a difference among the aforementioned formations only for the presence of sodium and potassium. In the case of sodium, there was a difference between the Barreiras and São Sebastião Formation and in the case of potassium; there were differences between the Barreiras Formations and the Marizal Formation, and between de Marizal Formation and the São Sebastião Formations respectively. The explanation for this phenomenon is the exchange of cations between sodium and calcium, regulated by pH due to the greater or lesser presence of the bicarbonate ion. This was strongly correlated to sodium $(r=0.70)$ in the São Sebastião Formation. Finally, the model used in this study showed that there is more evidence of ion exchange between the clay levels of the São Sebastião Formation and groundwater, than in relation to the other formations studied. This was to be expected, since the study area is a multi-layered aquifer consisting of several levels of clay.

Keywords: Hydrogeochemistry. Groundwater. Comparative study.

1 Universidade Federal da Bahia (UFBA) - E-mail: sergiomn@ufba.br

2 Universidade Federal da Bahia (UFBA) - E-mail: $\underline{\text { lrogerio@ufba.br }}$

3 Universidade Federal da Bahia (UFBA) - E-mail: carlos_cursos@hotmail.com 


\section{INTRODUÇÃO}

A utilização da água subterrânea tem aumentado de forma significativa na região do Recôncavo Norte da Bahia, principalmente quando se trata do aquífero São Sebastião. Além de apresentar quase sempre água doce de boa qualidade, poços perfurados nesse aquífero podem apresentar grandes vazões $\left(>300 \mathrm{~m}^{3} / \mathrm{h}\right)$ além de possuir uma reserva explorável (Re) avaliada em 14,74 x $10^{8} \mathrm{~m}^{3} / \mathrm{ano}$ (IBGE, 1999). É considerada a segunda maior do Estado devido as suas características litológicas predominantemente arenosas e elevadas espessuras com água doce que pode chegar até uma profundidade de 800 metros (UFBA,2012). Sotoposto a Formação São Sebastião pode ser encontrada em alguns locais da região do Recôncavo Norte, as Formações Barreiras e Marizal que apresentam juntas uma reserva explorável de 3,6 x $10^{7} \mathrm{~m}^{3}$ /ano (IBGE, 1999). As recargas de água para a Formação São Sebastião ocorrem predominantemente através das precipitações pluviométricas diretas nas camadas aflorantes, mas também se dá de forma indireta por meio dos aquíferos Barreiras e Marizal que funcionam, nesse caso, como armazenadores e reservatórios temporários situados sobre o aquífero São Sebastião. Em função disso, partiu-se da premissa de que não haveria diferença hidrogeoquímica significativa entre esses três aquíferos devido as suas interconexões hidráulicas a partir de áreas comuns de recargas alimentadas pelas águas meteóricas. Admitia-se, por exemplo, como hipótese de trabalho, que o ferro total seria um bom indicador para esse estudo, devido à existência de crostas ferruginosas situadas em determinados níveis das Formações Barreiras e Marizal sotopostas ao São Sebastião, conforme indicou Nascimento e Alves (2011) e Alves (2012). Posteriormente, Nascimento e Alves (2014) utilizando análise de variância (ANOVA) com os valores de cálcio, magnésio, cloreto, bicarbonato e ferro total obtidos nas águas subterrâneas nas regiões de Camaçarí/Dias d'Ávila não encontraram diferenças significativas entre a razão das variâncias desses parâmetros químicos obtidas dentro e entre esses três aquíferos, considerando um nível de significância de 5\%. Alves (2015), utilizando essa mesma técnica estatística encontrou diferença significativa para cálcio e magnésio entre os membros inferior, médio e superior da Formação São Sebastião.

Este trabalho teve como objetivo principal estabelecer uma diferenciação hidrogeoquímica entre as Formações Barreiras, Marizal e São Sebastião na região do Recôncavo Norte da Bahia. Para tanto foram definidos os seguintes objetivos específicos: a) definir as diferenças faciológicas e tipológicas dessas águas através das relações iônicas características; b) estabelecer a classificação hidroquimica das águas utilizando-se o diagrama triangular de Piper; c) estabelecer a diferenciação hidroquimica entre as águas subterrâneas dos três aquíferos utilizando-se a Analise de Variância (ANOVA)-fator único, complementado pelo teste de Tukey; e) investigar os processos de troca iônica segundo proposição de Schoeller (1962).

Assim, o propósito desse trabalho foi testar alguns parâmetros físico-químicos que servissem para diferenciar aquíferos sedimentares na região do Recôncavo Norte da Bahia.

\section{2 ÁREA DE ESTUDO}

A região do Recôncavo Norte abrange 40 municípios, destacando-se como os mais importantes: Alagoinhas, Camaçari, Dias D’Ávila, Entre Rios, Lauro de Freitas, Madre de Deus, Mata de São João, Simões Filho e Esplanada. Ocupa uma área total de $16.822,2 \mathrm{~km}^{2}$ equivalente a quase $3 \%$ da superfície total do Estado da Bahia. Segundo o Censo Demográfico do Instituto Brasileiro de Geografia e Estatística-IBGE (2000), os 40 municípios possuíam uma população urbana de 3.886.060 hab. equivalentes a 44,3\% do total da população urbana e de 4.237 .035 habitantes, equivalente a $2,4 \%$ da população total do Estado, abrigando a maior densidade populacional dentre as demais regiões do Estado, da ordem de $252 \mathrm{hab} / \mathrm{km}^{2}$, ou seja, 2,10 vezes maior que a média estadual. A grande expressão 
demográfica, juntamente com a presença de importantes centros urbanos pode ser explicada pelo potencial econômico das indústrias e serviços que atraem intensos fluxos migratórios. $\mathrm{O}$ contingente populacional continua em crescimento com a ampliação dos pólos industriais e do setor de serviços, aumentando com isso a demanda de água (SANTOS; OLIVEIRA, 2007).

Dentre os 10 primeiros municípios mais desenvolvidos do Estado, 7 se encontram nesta região: Salvador, Lauro de Freitas, Feira de Santana, Dias D’Ávila, Camaçari, Madre Deus e Simões Filho (SANTOS \& OLIVEIRA, 2007).

\section{O CONTEXTO LITO ESTRATIGRÁ- FICO}

A Formação Barreiras é caracterizada por sistemas de leques aluviais compostos de arenitos fluviais grosseiros, médios e finos, cinza-esbranquiçados e amareloavermelhados, pouco consolidados, com níveis conglomeráticos nas seções basais. Esses arenitos, normalmente, são portadores de estratificações cruzadas, mas ocorrem também horizontes maciços e níveis com estratos plano-paralelos. Contêm frequentes intercalações de folhelhos cinza-avermelhados, roxos amarelados. Distribuem-se geograficamente em discordância erosiva sobre os sedimentos das formações Marizal, São Sebastião e outras unidades estratigráficas da região (Figura 1).

A Formação Marizal é representada por clásticos grosseiros (conglomerados e arenitos), folhelhos e calcários representantes. Sua deposição é atribuída a sistemas aluviais desenvolvidos no contexto de uma subsidência termal, pós-rifte, atestada pela subhorizontalidade dos estratos. Esta unidade recobre, em discordância erosiva, os sedimentos da Formação São Sebastião. Compõe-se de arenitos cinza-esbranquiçados a amarelados, de granulação fina a média, maciços ou portando estratificações cruzadas acanaladas. Contém níveis de conglomerados na base e intercalações de siltitos, folhelhos e calcários.

A Formação São Sebastião foi depositada em ambientes continentais alternados entre planície fluvial, planície deltáica e um amplo lago raso (ABOARRAGE, 1970). Compõe-se de arenitos cinza-amarelados, róseos e amarelo-avermelhados, finos, médios a grosseiros, feldspáticos. Tais arenitos foram empilhados como corpos lateralmente contínuos, de geometria tabular, maciços ou com estratificação plano-paralela de baixo ângulo e/ou estratificações cruzadas acanaladas. Ocorrem também arenitos de frentes deltáicas, com geometrias de lobos ou sigmoidais. Estes possuem estratificações cruzadas acanaladas e plano-paralelas, marcas de ondas e numerosas intercalações de siltitos e folhelhos. Os depósitos lacustres são representados por camadas espessas e contínuas de folhelhos cinza-claros a cinzaavermelhados, com pequenas intercalações de siltitos, arenitos finos e calcários.

O sistema aquífero livre, na maior parte da região é basicamente constituído pelo acoplamento de arenitos das formações Marizal e São Sebastião formando um extenso reservatório com espessura média da ordem de $80 \mathrm{~m}$, mas que pode alcançar em regiões de baixos estruturais como os de Camaçari e de Alagoinhas, mais de $200 \mathrm{~m}$ de espessura (BRASIL, 2012). Localmente, é possível também que arenitos da Formação Barreiras possam fazer parte do mesmo sistema, mas a ocorrência dessa formação é mais restrita e ocupa zonas de tabuleiros mais elevados.

Em afloramentos e em perfis de poços, os arenitos da Formação São Sebastião se mostram como maciços ou com estratificações cruzadas de grande porte, granulação média a fina, mas com níveis esparsos de grânulos, seixos quartzosos e pelotas de argila; tornam-se finamente granulados, argilosos e com estratificação plano-paralela no topo sendo recobertos por folhelhos avermelhados bandeados com siltitos e arenitos, que podem alcançar até $20 \mathrm{~m}$ de espessura. As sequências predominantemente arenosas resultaram de extensas e prolongadas deposições fluviais em sistemas de correntes entrelaçadas muito 
móveis, que operaram com fortes gradientes hidráulicos. Os corpos de folhelhos representam depósitos de planície de inundação e/ou de preenchimento de meandros abandonados ou ainda, deposições lacustres de águas rasas.



Figura 1- Distribuição das Formações Barreiras, Marizal e São Sebastião na região do recôncavo norte da Bahia Figure 1- Distribution of Barreiras, Marizal and São Sebastião Formations in Recôncavo Norte region of Bahia

\section{MATERIAL E MÉTODO}

Os dados hidroquimicos utilizados nesse trabalho foram obtidos no Sistema de Informações de Água Subterrânea da Companhia de Pesquisa e Recursos Minerais (CPRM) e nos arquivos da Companhia de Engenharia Ambiental e Recursos Hídricos da Bahia (CERB). Através de planilha Excel esses dados foram processados pelo progra- ma de Estatística do Excel, obtendo-se Análise de Variância (Anova)-fator único, complementado pelo teste de Tukey. Para estabelecer a classificação das águas utilizou-se o diagrama triangular de PIPER (1944) confeccionado através do programa Qualigraf - modelo 2014, da Fundação Cearense de Meteorologia (FUNCEME) cujos resultados foram apresentados nesse artigo sob a forma de figuras e tabelas. Os tipos ou fácies hidro- 
químicos foram obtidos através das relações iônicas características entre o $\mathrm{Ca}^{++}, \mathrm{Mg}^{++}$, $\mathrm{Na}^{+}, \mathrm{K}^{+}, \mathrm{Cl}^{-} \mathrm{SO}^{4}, \mathrm{CO}^{3}$ e $\mathrm{HCO}^{3}$ fazendo a conversão dos valores de mg. $\mathrm{L}^{-1}$ (miligrama por litro) para mEq. $\mathrm{L}^{-1}$ (miliequivalente grama por litro). Finalmente, para identificar se houve processos de troca catiônica entre a água e as litologias existentes nas três formações estudadas utilizou-se o modelo de Schoeller (1962), in Fenzl (1986).

\section{RESULTADOS OBTIDOS E DISCUS- SÃO}

\subsection{Classificação das águas e relações iôni- cas características}

Formação Barreiras - Para uma população de 32 poços tubulares estudados pode-se afirmar que as águas subterrâneas dessa Formação são classificadas como cloretadas sódicas numa frequência de $56 \%$ dos pontos estudados, bicarbonatadas sódicas em $16 \%$, sódicas mistas em $6 \%$, bicarbonatadas cálcicas em $3 \%$, cálcicas mistas em $6 \%$, cloretada mista 6\% e bicarbonatadas mistas 6\%. (Tabela 1). O cátion predominante é o sódio detectado em $78 \%$ dos poços estudados, enquanto o cloreto se destaca entre os anions em $62 \%$ dos poços, vindo em seguida o bicarbonato em $25 \%$ dos poços estudados. De um modo geral, as águas cloretadas sódicas são normalmente localizadas em coberturas de areias e arenitos enquanto as bicarbonatadas sódicas e cálcicas podem ser encontradas também em coberturas detríticas lateríticas desenvolvidas sobre rochas do embasamento cristalino. Essas coberturas detríticas lateríticas são comumente confundidas com a Formação Barreiras nos tabuleiros litorâneos do Estado da Bahia. Na Formação Barreiras, as águas subterrâneas evoluem hidroquimicamente de sódica para mista (sódica-cálcica) até atingir sua condição de puramente cálcica. Entre os anions as águas subterrâneas evoluem de cloretadas para mista (cloretadabicarbonatada) e finalmente para bicarbonatada conforme assinala o diagrama triangular de Piper (Figura 2).

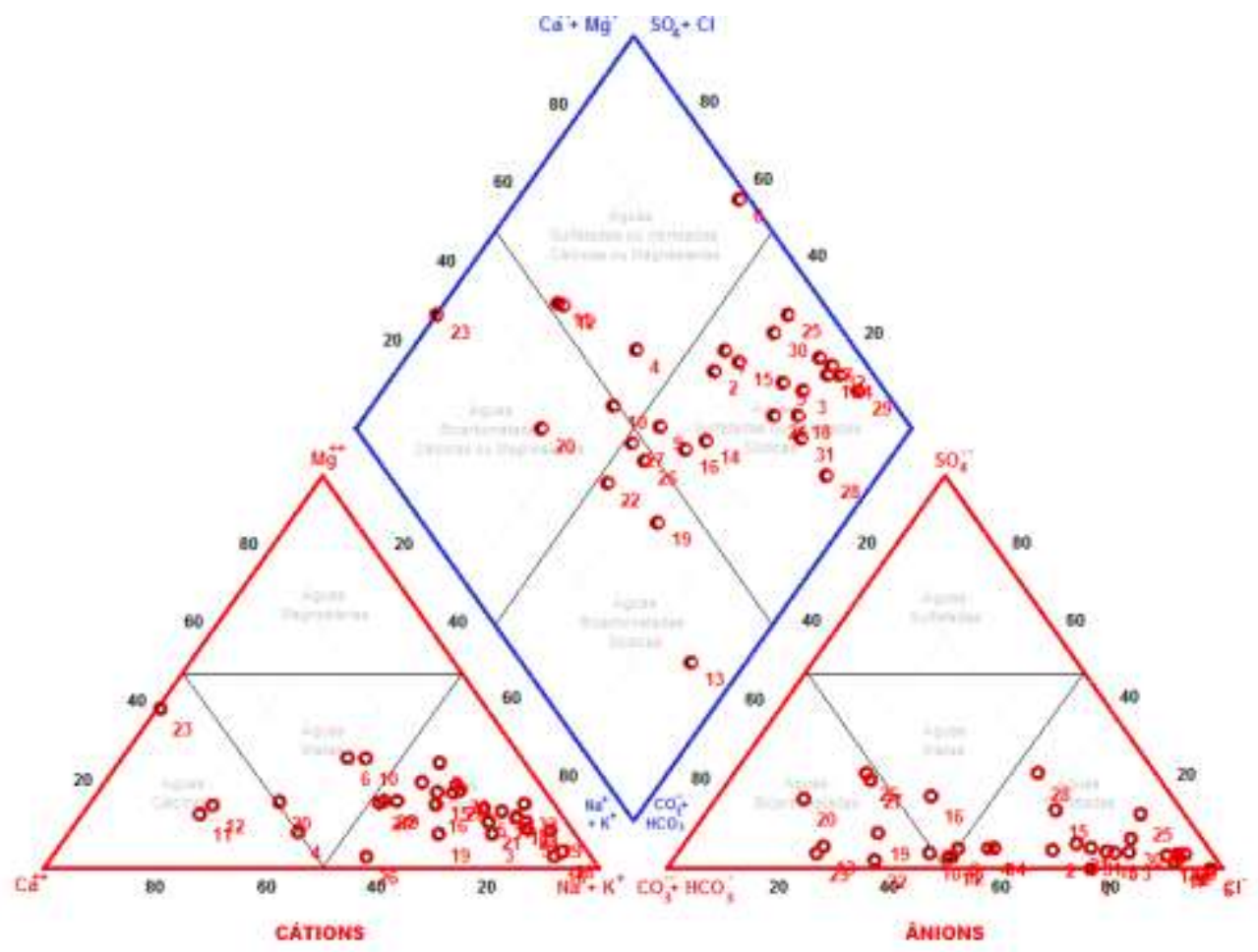

Figura 2 - Classificação das águas subterrâneas da Formação Barreiras Figure 2 - Groundwater classification of the Barreiras Formation 
Tabela 1 - Classificação da água subterrânea na Formação Barreiras

Table 1 - Groundwater classification of the Barreiras Formation

\begin{tabular}{cccccc}
\hline Classes de Água & $\mathbf{N}^{\mathbf{0}}$ & $\boldsymbol{\%}$ & Classes de Água & $\mathbf{N}^{\mathbf{0}}$ & \% \\
\hline Sódicas & 25 & 78 & Cloretadas & 20 & 62 \\
Cálcicas & 3 & 9 & Bicarbonatadas & 8 & 25 \\
Magnesianas & 0 & 0 & Sulfatadas & 0 & 0 \\
Mistas (cátions) & 4 & 12 & Mistas (anions) & 4 & 12 \\
Cloretadas sódicas & 18 & 56 & Cloretadas Magnesianas & 0 & 0 \\
Bicarbonatadas sódicas & 5 & 16 & Bicarbonatadas Magnesianas & 0 & 0 \\
Sulfatadas sódicas & 0 & 0 & Sulfatadas Magnesianas & 0 & 0 \\
Sódicas Mistas & 2 & 6 & Magnesianas Mistas & 0 & 0 \\
Cloretadas cálcicas & 0 & 0 & Cloretadas Mistas & 2 & 6 \\
Bicarbonatadas Cálcicas & 1 & 3 & Bicarbonatadas Mistas & 2 & 6 \\
Sulfatadas cálcicas & 0 & 0 & Sulfatadas Mistas & 0 & 0 \\
Calcicas Mistas & 2 & 6 & Mistas & 0 & 0 \\
\hline
\end{tabular}

As relações aniônicas predominantes tipo $\mathrm{rHCO}_{3}>\mathrm{rCl}>\mathrm{rSO}_{4}$ em $19,4 \%$ dos poços nas águas subterrâneas da Formação Barreiras são do tipo $\mathrm{rCl}>\mathrm{rHCO} 3>\mathrm{rSO} 4$ em $77,8 \%$ dos poços tubulares estudados. Dentro desse grupo, as relações catiônicas presentes são $\mathrm{rNa}>\mathrm{rMg}>\mathrm{rCa}$ com $41,7 \%$ e $\mathrm{rNa}>\mathrm{rCa}>\mathrm{rMg}$ com $36,1 \%$ dos poços tubulares estudados (Tabela 2).

Secundariamente, as relações aniônicas características nessa Formação são do tubulares estudados. Dentro desse grupo, as relações catiônicas presentes são do tipo $\mathrm{rNa}>\mathrm{rCa}>\mathrm{rMg}$ com $16,6 \%$ e $\mathrm{rCa}>\mathrm{rMg}>\mathrm{rNa}$ com 2,8\% dos poços tubulares. Finalmente, sem maior expressividade ocorre a relação aniônica do tipo $\mathrm{rHCO}_{3}>\mathrm{rSO}_{4}>\mathrm{Cl}$ com os cátions obedecendo a seguinte ordem: $\mathrm{rCa}>\mathrm{rNa}>\mathrm{rMg}$ em $2,8 \%$ dos poços tubulares estudados (Tabela 2).

Tabela 2 - Relações iônicas características- Formação Barreiras (em mEq.L $\mathrm{L}^{-1}$ )

Table 2 - Ionic relation caracter of the Barreiras Formation (in mEq. $\mathrm{L}^{-1}$ )

\begin{tabular}{|c|c|c|c|c|}
\hline Anions & Cátions & Poços Tubulares & $\%$ & $\%$ \\
\hline \multirow{2}{*}{$\mathrm{rCl}>\mathrm{rHCO}_{3}>\mathrm{rSO}_{4}$} & $\mathrm{rNa}>\mathrm{rMg}>\mathrm{rCa}$ & 15 & 41,7 & \multirow{2}{*}{$\mathbf{7 7 , 8}$} \\
\hline & $\mathrm{rNa}>\mathrm{rCa}>\mathrm{rMg}$ & 13 & 36,1 & \\
\hline \multirow{2}{*}{$\mathrm{rHCO}_{3}>\mathbf{r C l}>\mathrm{rSO}_{4}$} & $\mathrm{rNa}>\mathrm{rCa}>\mathrm{rMg}$ & 06 & 16,6 & \multirow{2}{*}{19,4} \\
\hline & $\mathrm{rCa}>\mathrm{rMg}>\mathrm{rNa}$ & 01 & 2,8 & \\
\hline $\mathrm{rHCO}_{3}>\mathrm{rSO}_{4}>\mathrm{rCl}$ & \multirow[t]{2}{*}{$\mathrm{rCa}>\mathrm{rNa}>\mathrm{rMg}$} & 01 & 2,8 & 2,8 \\
\hline TOTAL & & 36 & 100 & \\
\hline
\end{tabular}

Formação Marizal - As águas subterrâneas da Formação Marizal podem ser classificadas preferencialmente como cloretadas sódicas em $55 \%$ dos pontos estudados, bicarbonatada sódica em $15 \%$, sódicas mistas em $5 \%$, bicarbonatada cálcica em 5\%, cloretada magnesiana em $5 \%$, cloretadas mistas em $5 \%$, bicarbonatadas mistas em 5\% e mistas-mistas em 5\%. (Tabela 3). O cátion predominante é o sódio em $75 \%$ dos poços estudados enquanto o anion predominante é o cloreto, detectado em $65 \%$ dos poços, vindo em seguida o bicarbonato detectado em $25 \%$ dos poços estudados, portanto apresentam características bem semelhantes às águas da Formação Barreiras.

Na Formação Marizal, os cátions presentes nas águas subterrâneas evoluem hidroquimicamente de sódica para mista (sódica-cálcica) até atingir a condição de eminentemente cálcica. Entre os anions as águas subterrâneas evoluem também de cloretadas para mista (cloretada-bicarbonatada) e finalmente para bicarbonatada, conforme assinala o diagrama triangular de Piper (Figura 3). 


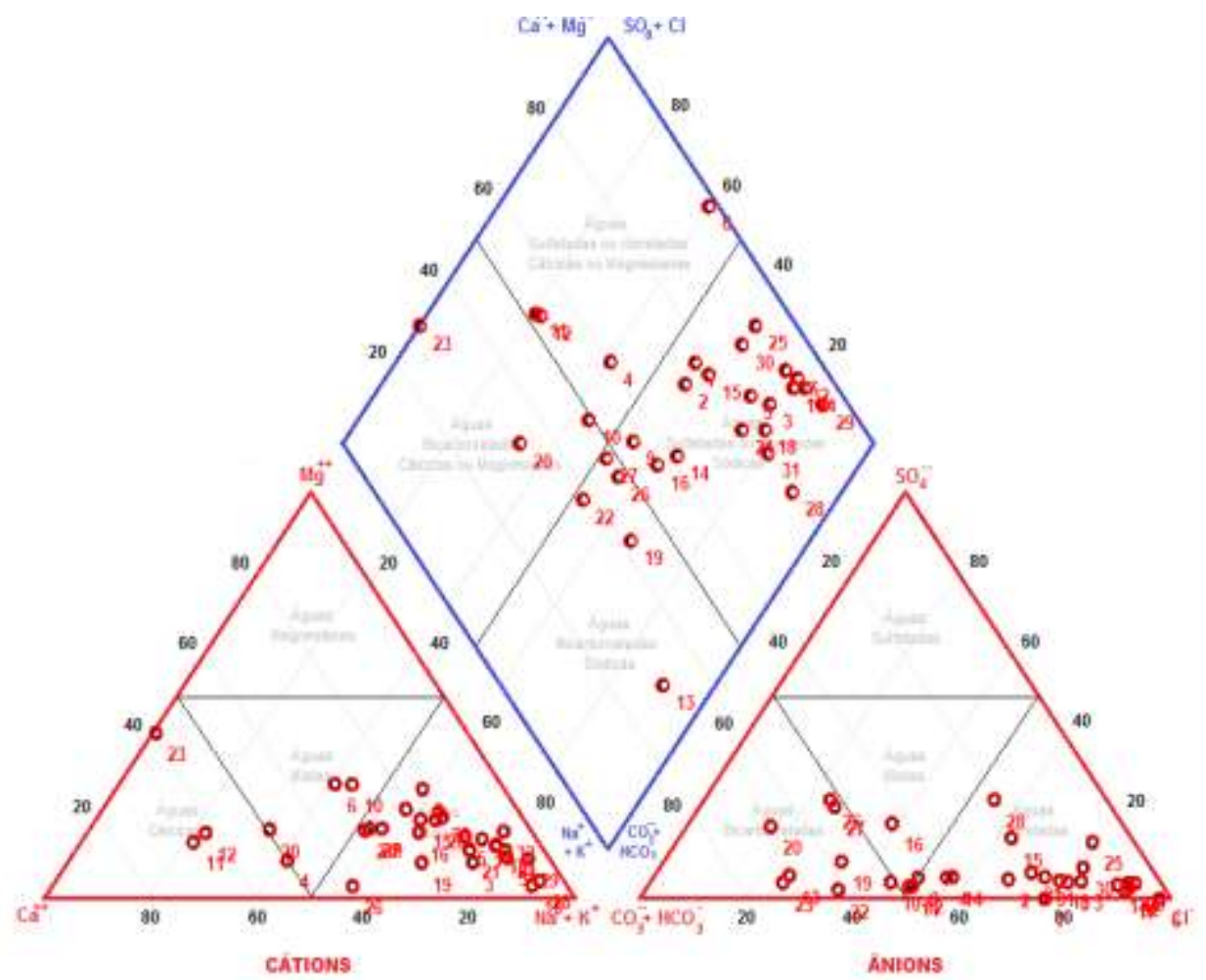

Figura 3 - Classificação das águas subterrâneas da Formação Marizal Figure 3 - Groundwater classification of Marizal Formation

Tabela 3 - Classificação das águas subterrâneas - Formação Marizal

Table 3 - Groundwater classification of Marizal Formation

\begin{tabular}{cccccc}
\hline Classes de Água & $\mathbf{N}^{\mathbf{0}}$ & $\mathbf{\%}$ & Classes de Água & $\mathbf{N}^{\mathbf{0}}$ & \% \\
\hline Sódicas & 15 & 75 & Cloretadas & 13 & 65 \\
Cálcicas & 1 & 5 & Bicarbonatadas & 5 & 25 \\
Magnesianas & 1 & 5 & Sulfatadas & 0 & 0 \\
Mistas (cátions) & 3 & 15 & Mistas (anions) & 2 & 10 \\
Classes de Água & $\mathbf{N}^{\mathbf{0}}$ & $\boldsymbol{\%}$ & Classes de Água & $\mathbf{N}^{\mathbf{0}}$ & \% \\
Cloretadas sódicas & 11 & 55 & Cloretadas Magnesianas & 1 & 5 \\
Bicarbonatadas sódicas & 3 & 15 & Bicarbonatadas Magnesianas & 0 & 0 \\
Sulfatadas sódicas & 0 & 0 & Sulfatadas Magnesianas & 0 & 0 \\
Sódicas Mistas & 1 & 5 & Magnesianas Mistas & 0 & 0 \\
Cloretadas cálcicas & 0 & 0 & Cloretadas Mistas & 1 & 5 \\
Bicarbonatadas Cálcicas & 1 & 5 & Bicarbonatadas Mistas & 1 & 5 \\
Sulfatadas cálcicas & 0 & 0 & Sulfatadas Mistas & 0 & 0 \\
Calcicas Mistas & 0 & 0 & Mistas & 1 & 5 \\
\hline
\end{tabular}

As relações aniônicas predominantes são do tipo $\mathrm{rCl}>\mathrm{rHCO} 3 \mathrm{HCO}_{3} \mathrm{em} 81,8 \%$ dos poços tubulares estudados. Dentro desse grupo, as relações catiônicas presentes são $\mathrm{rNa}>\mathrm{rMg}>\mathrm{rCa}$ com $31,8 \%$ e $\mathrm{rNa}>\mathrm{rCa}>\mathrm{rMg}$ com $45,5 \%$ dos poços tubulares estudados, além da relação $\mathrm{rCa}>\mathrm{rMg}>\mathrm{rNa}$ em 4,5\% dos poços (Tabela 4). 
Tabela 4 - Relações iônicas características- Formação Marizal (em mEq.L-1 ${ }^{-1}$

Table 4 - Ionic relation caracteristic of Marizal Formation (in mEq.L $\mathrm{L}^{-1}$ )

\begin{tabular}{|c|c|c|c|c|}
\hline Anions & Cátions & Poços Tubulares & $\%$ & $\%$ \\
\hline \multirow{3}{*}{$\mathrm{rCl}>\mathrm{rHCO}_{3}>\mathrm{rSO}_{4}$} & $\mathrm{rNa}>\mathrm{rMg}>\mathrm{rCa}$ & 7 & 31,8 & \multirow{3}{*}{81,8} \\
\hline & $\mathrm{rNa}>\mathrm{rCa}>\mathrm{rMg}$ & 10 & 45,5 & \\
\hline & $\mathrm{rCa}>\mathrm{rMg}>\mathrm{rNa}$ & 01 & 4,5 & \\
\hline \multirow{2}{*}{$\mathrm{rHCO}_{3}>\mathrm{rCl}>\mathrm{rSO}_{4}$} & $\mathrm{rNa}>\mathrm{rMg}>\mathrm{rCa}$ & 2 & 9,0 & \multirow{2}{*}{13,6} \\
\hline & $\mathrm{rNa}>\mathrm{rCa}>\mathrm{rMg}$ & 01 & 4,6 & \\
\hline $\mathrm{rCl}>\mathrm{rSO}_{4}>\mathrm{rHCO}_{3}$ & $\mathrm{rNa}>\mathrm{rCa}>\mathrm{rMg}$ & 01 & 4,6 & 4,6 \\
\hline \multicolumn{2}{|c|}{ TOTAL } & 22 & 100 & 100 \\
\hline
\end{tabular}

Secundariamente, as relações aniônicas características nessa Formação são do tipo rHCO $3>\mathrm{rCl}>\mathrm{rSO} 4$ em $13,6 \%$ dos poços tubulares estudados. Dentro desse grupo, as relações catiônicas presentes são $\mathrm{rNa}>\mathrm{rMg}>\mathrm{rCa}$ com $9,0 \%$ e $\mathrm{rNa}>\mathrm{rCa}>\mathrm{rMg}$ com $4,6 \%$ respectivamente. Finalmente, sem maior expressividade ocorre a relação aniônica $\mathrm{rCl}>\mathrm{rSO}_{4}>\mathrm{HCO}_{3}$ com os cátions $\mathrm{rNa}>\mathrm{rCa}>\mathrm{rMg}$ em $4,6 \%$ dos poços tubulares.

Formação São Sebastião - As águas subterrâneas da Formação São Sebastião foram classificadas preferencialmente como clore- tadas sódicas em $22 \%$ dos pontos estudados, bicarbonatada sódica em $22 \%$, sódicas mistas em $4 \%$, cloretadas cálcicas em $7 \%$, bicarbonatadas cálcicas em $7 \%$, cloretadas mistas em $22 \%$ e bicarbonatadas mistas em $15 \%$ dos pontos estudados (Tabela 5). Na Formação São Sebastião, o cátion predominante é o sódio verificado em $48 \%$ dos poços estudados, enquanto o anion que mais se destacou foi o cloreto em $52 \%$ dos poços estudados, vindo em seguida o bicarbonato em $44 \%$ dos poços (Figura 4).

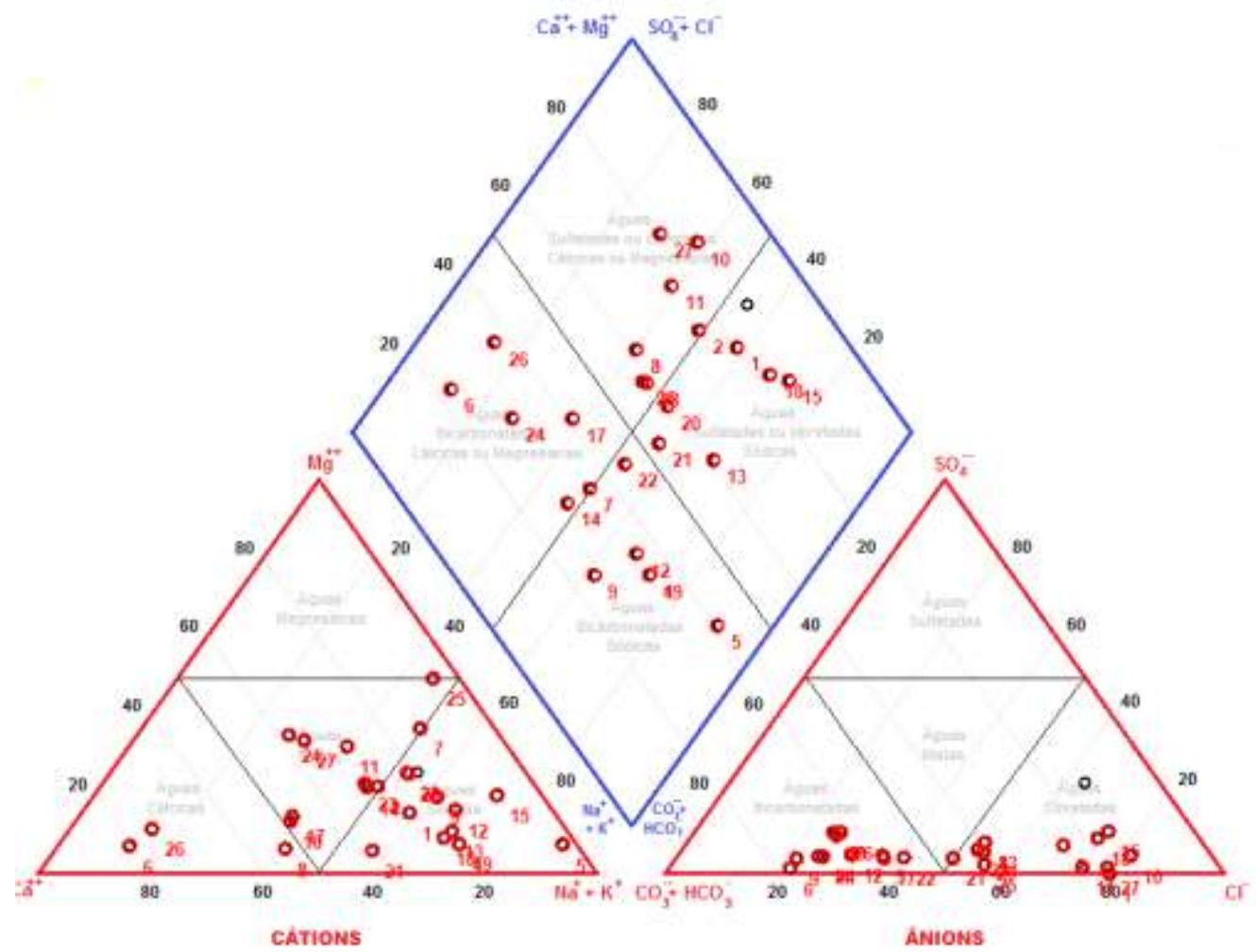

Figura 4 - Classificação da água subterrânea na Formação São Sebastião

Figure 4 - Groundwater classification of São Sebastião Formation 
Tabela 5 - Classificação da água subterrânea na Formação São Sebastião

Table 5 - Classification of groundwater of the São Sebastião Formation

\begin{tabular}{cccccc}
\hline Classes de Água & $\mathbf{N}^{\mathbf{0}}$ & $\boldsymbol{\%}$ & Classes de Água & $\mathbf{N}^{\mathbf{0}}$ & \% \\
\hline Sódicas & 13 & 48 & Cloretadas & 14 & 52 \\
Cálcicas & 4 & 15 & Bicarbonatadas & 12 & 44 \\
Magnesianas & 0 & 0 & Sulfatadas & 0 & 0 \\
Mistas (cátions) & 10 & 37 & Mistas (anions) & 1 & 4 \\
Classes de Água & $\mathbf{N}^{\mathbf{o}}$ & $\boldsymbol{\%}$ & Classes de Água & $\mathbf{N}^{\mathbf{o}}$ & $\boldsymbol{\%}$ \\
Cloretadas sódicas & 6 & 22 & Cloretadas Magnesianas & 0 & 0 \\
Bicarbonatadas sódicas & 6 & 22 & Bicarbonatadas Magnesianas & 0 & 0 \\
Sulfatadas sódicas & 0 & 0 & Sulfatadas Magnesianas & 0 & 0 \\
Sódicas Mistas & 1 & 4 & Magnesianas Mistas & 0 & 0 \\
Cloretadas cálcicas & 2 & 7 & Cloretadas Mistas & 6 & 22 \\
Bicarbonatadas Cálcicas & 2 & 7 & Bicarbonatadas Mistas & 4 & 15 \\
Sulfatadas cálcicas & 0 & 0 & Sulfatadas Mistas & 0 & 0 \\
Calcicas Mistas & 0 & 0 & Mistas & 0 & 0 \\
\hline
\end{tabular}

As relações aniônicas predominantes nas águas subterrâneas da Formação São Sebastião são do tipo $\mathrm{rCl}>\mathrm{rHCO}_{3}>\mathrm{rSO}_{4}$ em $55,5 \%$ dos 27 poços tubulares estudados. Dentro desse grupo, as relações catiônicas presentes são $\mathrm{rNa}>\mathrm{rMg}>\mathrm{rCa}$ com $18,5 \%$, $\mathrm{rNa}>\mathrm{rCa}>\mathrm{rMg}$ com $22,2 \%$ e $\mathrm{rCa}>\mathrm{rNa}>\mathrm{rMg}$ em $14,8 \%$ dos poços (Tabela 6).

Secundariamente, as relações aniônicas características nessa Formação são do tipo $\mathrm{rHCO}_{3}>\mathrm{rCl}>\mathrm{rSO}_{4}$ em $44,5 \%$ dos 27 poços tubulares estudados. Dentro desse grupo, as relações catônicas presentes são $\mathrm{rNa}>\mathrm{rMg}>\mathrm{rCa}$ com $18,5 \%, \quad \mathrm{rNa}>\mathrm{rCa}>\mathrm{rMg}$ com $11,2 \%$ e $\mathrm{rCa}>\mathrm{rNa}>\mathrm{rMg}$ em $14,8 \%$ dos poços tubulares. As águas bicarbonatadas da Formação São Sebastião provêm de arenitos amarelos e avermelhados, com granulação variada por vezes com matriz siltosa e argilosa, quase sempre intercalados por folhelhos e camadas de argilas. Essas intercalações de folhelhos formam aquíferos semi-confinados à confinados e, raramente freáticos.

Tabela 6 - Relações iônicas características - Formação São Sebastião (em mEq.L ${ }^{-1}$ )

Table 6 - Ionic relation characteristic of the São Sebastião Formation (in mEq. $\mathrm{L}^{-1}$ )

\begin{tabular}{|c|c|c|c|c|}
\hline Anions & Cátions & Poços Tubulares & $\%$ & $\%$ \\
\hline & $\mathrm{rNa}>\mathrm{rMg}>\mathrm{rCa}$ & 05 & 18,8 & \\
\hline \multirow[t]{3}{*}{$\mathrm{rCl}>\mathrm{rHCO}_{3}>\mathrm{rSO}_{4}$} & $\mathrm{rNa}>\mathrm{rCa}>\mathrm{rMg}$ & 06 & 22,2 & $\mathbf{5 5 , 5}$ \\
\hline & $\mathrm{rCa}>\mathrm{rNa}>\mathrm{rMg}$ & 04 & 14,8 & \\
\hline & $\mathrm{rNa}>\mathrm{rMg}>\mathrm{rCa}$ & 05 & 18,5 & \\
\hline \multirow[t]{3}{*}{$\mathrm{rHCO}_{3}>\mathrm{rCl}>\mathrm{rSO}_{4}$} & $\mathrm{rNa}>\mathrm{rCa}>\mathrm{rMg}$ & 03 & 11,2 & 44,5 \\
\hline & $\mathrm{rCa}>\mathrm{rNa}>\mathrm{rMg}$ & 04 & 14,8 & \\
\hline & & 27 & 100 & 100 \\
\hline
\end{tabular}

$\mathrm{r}=$ miliequivalente por litro

\subsection{Análise de variância (Anova) - Fator único}

Para a realização dos cálculos da análise de variância utilizou-se os parâmetros cálcio, magnésio, sódio, potássio, cloreto, bicarbonato, sulfato, ferro total, dureza total e condutividade elétrica e sulfato obtidos nas análises de águas subterrâneas oriundas das Formações Barreiras, Marizal e São Sebastião (Tabela 7). Partiu-se da hipótese nula $\left(\mathrm{H}_{0}\right)$ de que não haveria diferença significativa da 
razão entre a variância das médias das Formações estudadas $\left(\mathrm{S}_{\mathrm{x}}{ }^{2}\right)$ e a variância dentro de cada Formação $\left(\mathrm{S}_{\mathrm{p}}{ }^{2}\right)$. Os resultados mostraram que a razão-F calculado pela divisão $\mathrm{nS}_{\mathrm{x}}{ }^{2} / \mathrm{S}_{\mathrm{p}}^{2}$ foi sempre menor do que um $\mathrm{F}$ crítico tabelado ao nível de significância de $\alpha=$ 0,05 para todos os parâmetros referidos acima com exceção do sódio e do potássio cujo $\mathrm{F}$ calculado foi maior do que o $\mathrm{F}$ tabelado. Considerou-se, em todos os casos, um grau de liberdade $\mathrm{C}=2$ e $\mathrm{C}(\mathrm{n}-1)$ sendo que este último variou conforme o parâmetro utilizado (Tabela 7). Para a hipótese Ho ter aceitabilidade e credibilidade e, consequentemente, ser aceita, o valor-p da probabilidade teria que ser maior do que o nível de significância adotado, ou seja, 0,05 (WONNACOTT e WONNACOTT, 1985). Para todos os parâmetros utilizados $p>0,05$. No entanto o sódio e o potássio apresentaram uma probabilidade $p<0,05$ (Tabela 7).

Tabela 7 - Análise de variância - ANOVA (fator único)

Table 7 - Analysis of variance - ANOVA (oneway) (continua)

\begin{tabular}{|c|c|c|c|c|c|c|}
\hline RESUMO & CALCIO & & & & & \\
\hline Grupo & Contagem & Soma & Média & Variância & & \\
\hline $\mathrm{Tb}$ & 36 & 575,87 & 16,00 & 452,22 & & \\
\hline $\mathrm{Km}$ & 21 & 424,67 & 20,22 & 893,19 & & \\
\hline Kss & 27 & 348,58 & 12,91 & 175,39 & & \\
\hline \multicolumn{7}{|l|}{ ANOVA } \\
\hline Fonte da variação & $S Q$ & $g l$ & $M Q$ & $F$ & valor- $P$ & F crítico \\
\hline Entre grupos & 631,82 & 2 & 315,91 & 0,67 & 0,52 & 3,11 \\
\hline Dentro dos grupos & 38251,61 & 81 & 472,24 & & & \\
\hline Total & 38883,43 & 83 & & & & \\
\hline RESUMO & MAGNÉSIO & & & & & \\
\hline Grupo & Contagem & Soma & Média & Variância & & \\
\hline $\mathrm{Tb}$ & 36 & 208,61 & 5,79 & 19,43 & & \\
\hline $\mathrm{Km}$ & 23 & 247,47 & 10,76 & 328,48 & & \\
\hline Kss & 27 & 348,58 & 12,91 & 175,39 & & \\
\hline \multicolumn{7}{|l|}{ ANOVA } \\
\hline Fonte da variação & $S Q$ & $g l$ & $M Q$ & $F$ & valor- $P$ & F crítico \\
\hline Entre grupos & 842,99 & 2 & 421,50 & 2,81 & 0,07 & 3,11 \\
\hline Dentro dos grupos & 12466,41 & 83 & 150,20 & & & \\
\hline Total & 13309,407 & 85 & & & & \\
\hline RESUMO & CLORETO & & & & & \\
\hline Grupo & Contagem & Soma & Média & Variância & & \\
\hline $\mathrm{Tb}$ & 36 & 3488,04 & 96,89 & 49877,78 & & \\
\hline $\mathrm{Km}$ & 23 & 1501,76 & 65,29 & 10749,81 & & \\
\hline Kss & 27 & 537,9 & 19,92 & 203,04 & & \\
\hline \multicolumn{7}{|l|}{ ANOVA } \\
\hline Fonte da variação & $S Q$ & $g l$ & $M Q$ & $F$ & valor- $P$ & F crítico \\
\hline Entre grupos & 91432,015 & 2 & 45716,01 & 1,91 & 0,15 & 3,11 \\
\hline Dentro dos grupos & 1987497,3 & 83 & 23945,75 & & & \\
\hline Total & 2078929,3 & 85 & & & & \\
\hline
\end{tabular}


Tabela 7 - Análise de variância - ANOVA (fator único)

Table 7 - Analysis of variance - ANOVA (oneway)

RESUMO BICARBONATO

\begin{tabular}{|c|c|c|c|c|c|c|}
\hline Grupo & Contagem & Soma & Média & Variância & & \\
\hline $\mathrm{Tb}$ & 36 & 1641,52 & 45,597778 & 2446,052 & & \\
\hline $\mathrm{Km}$ & 23 & 606,93 & 26,388261 & 420,48619 & & \\
\hline Kss & 27 & 1107,89 & 41,032963 & 1762,2541 & & \\
\hline \multicolumn{7}{|l|}{ ANOVA } \\
\hline Fonte da variação & $S Q$ & $g l$ & $M Q$ & $F$ & valor $-P$ & $F$ crítico \\
\hline Entre grupos & 5336,917 & 2 & 2668,4585 & 1,57 & 0,21 & 3,11 \\
\hline Dentro dos grupos & 140681,12 & 83 & 1694,9533 & & & \\
\hline Total & 146018,04 & 85 & & & & \\
\hline RESUMO & FERRO TOTAL & & & & & \\
\hline Grupo & Contagem & Soma & Média & Variância & & \\
\hline $\mathrm{Tb}$ & 18 & 13,64 & 0,76 & 0,96 & & \\
\hline $\mathrm{Km}$ & 14 & 7,13 & 0,51 & 0,11 & & \\
\hline Kss & 19 & 7,9 & 0,42 & 0,16 & & \\
\hline \multicolumn{7}{|l|}{ ANOVA } \\
\hline Fonte da variação & $S Q$ & $g l$ & $M Q$ & $F$ & valor $-P$ & F crítico \\
\hline Entre grupos & 1,13 & 2 & 0,57 & 1,33 & 0,27 & 3,19 \\
\hline Dentro dos grupos & 20,53 & 48 & 0,43 & & & \\
\hline Total & 21,66 & 50 & & & & \\
\hline RESUMO & SODIO & & & & & \\
\hline Grupo & Contagem & Soma & Média & Variância & & \\
\hline $\mathrm{Tb}$ & 34 & 1602,29 & 47,13 & 2317,12 & & \\
\hline $\mathrm{Km}$ & 21 & 650,1 & 30,96 & 1408,94 & & \\
\hline Kss & 26 & 555,15 & 21,35 & 475,75 & & \\
\hline \multicolumn{7}{|l|}{ ANOVA } \\
\hline Fonte da variação & $S Q$ & $g l$ & $M Q$ & $F$ & valor- $P$ & $F$ crítico \\
\hline Entre grupos & 10176,451 & 2 & 5088,23 & 3,406 & 0,038 & 3,114 \\
\hline Dentro dos grupos & 116537,64 & 78 & 1494,07 & & & \\
\hline Total & 126714,09 & 80 & & & & \\
\hline RESUMO & POTASSIO & & & & & \\
\hline Grupo & Contagem & Soma & Média & Variância & & \\
\hline $\mathrm{Tb}$ & 33 & 182,45 & 5,53 & 14,97 & & \\
\hline $\mathrm{Km}$ & 20 & 188,4 & 9,42 & 67,47 & & \\
\hline Kss & 26 & 132,82 & 5,11 & 8,07 & & \\
\hline \multicolumn{7}{|l|}{ ANOVA } \\
\hline Fonte da variação & $S Q$ & $g l$ & $M Q$ & $F$ & valor-P & $F$ crítico \\
\hline $\begin{array}{l}\text { Entre grupos } \\
\text { Dentro dos }\end{array}$ & 250,78 & 2 & 125,39 & 4,86 & 0,01 & 3,12 \\
\hline grupos & 1962,78 & 76 & 25,83 & & & \\
\hline Total & 2213,56 & 78 & & & & \\
\hline
\end{tabular}


Tabela 7 - Análise de variância - ANOVA (fator único)

Table 7 - Analysis of variance - ANOVA (oneway)

\begin{tabular}{|c|c|c|c|c|c|c|}
\hline \multicolumn{5}{|c|}{ DUREZA TOTAL } & & \\
\hline Grupo & Contagem & Soma & Média & Variância & & \\
\hline $\mathrm{Tb}$ & 33 & 1175,81 & 35,63 & 1636,69 & & \\
\hline $\mathrm{Km}$ & 21 & 1297,33 & 61,78 & 10546,11 & & \\
\hline Kss & 25 & 640,92 & 25,64 & 511,80 & & \\
\hline \multicolumn{7}{|l|}{ ANOVA } \\
\hline Fonte da variação & $S Q$ & $g l$ & $M Q$ & $F$ & valor- $P$ & $F$ crítico \\
\hline Entre grupos & 15720,404 & 2 & 7860,20 & 2,17 & 0,12 & 3,12 \\
\hline Dentro dos grupos & 275579,35 & 76 & 3626,04 & & & \\
\hline Total & 291299,75 & 78 & & & & \\
\hline RESUMO & \multicolumn{4}{|c|}{ CONDUTIVIDADE ELETRICA } & & \\
\hline Grupo & Contagem & Soma & Média & Variância & & \\
\hline $\mathrm{Tb}$ & 34 & 12137,75 & 356,99 & 90667,30 & & \\
\hline $\mathrm{Km}$ & 21 & 5820,40 & 277,16 & 120988,90 & & \\
\hline Kss & 26 & 4827,94 & 185,69 & 20153,46 & & \\
\hline \multicolumn{7}{|l|}{ ANOVA } \\
\hline Fonte da variação & $S Q$ & $g l$ & $M Q$ & $F$ & valor-P & $F$ crítico \\
\hline Entre grupos & 432831,48 & 2 & 216415,74 & 2,85 & 0,06 & 3,11 \\
\hline Dentro dos grupos & 5915635,4 & 78 & 75841,48 & & & \\
\hline Total & 6348466,9 & 80 & & & & \\
\hline RESUMO & SULFATO & & & & & \\
\hline Grupo & Contagem & Soma & Média & Variância & & \\
\hline $\mathrm{Tb}$ & 35 & 707,34 & 20,21 & 4169,05 & & \\
\hline $\mathrm{Km}$ & 18 & 208,637 & 11,59 & 1198,39 & & \\
\hline Kss & 27 & 121,41 & 4,50 & 22,88 & & \\
\hline \multicolumn{7}{|l|}{ ANOVA } \\
\hline Fonte da variação & $S Q$ & $g l$ & $M Q$ & $F$ & valor- $P$ & F crítico \\
\hline Entre grupos & 3807,23 & 2 & 1903,62 & 0,90 & 0,41 & 3,12 \\
\hline Dentro dos grupos & 162715,22 & 77 & 2113,18 & & & \\
\hline Total & 166522,45 & 79 & & & & \\
\hline
\end{tabular}

A analise de variância ANOVA para o sódio e o potássio mostrou uma rejeição para a hipótese $\mathrm{H}_{0}$ quando o $\mathrm{F}$ calculado $>\mathrm{F}$ tabelado para um nível de significância de $5 \%$, ou seja, existe uma diferença entre as variâncias das médias das Formações Barreiras (Tb), Marizal (Km) e São Sebastião (Kss) quando comparada às variâncias calculadas dentro de cada Formação. Para verificar qual dessas Formações estaria destacando-se das demais com relação ao sódio e o potássio, foi utilizado o teste de TUKEY que é um teste complementar da Análise de Variância-

\section{ANOVA.}

Para o elemento sódio iniciou-se com o cálculo da diferença mínima significativa (d.m.s), através da seguinte fórmula:

$$
\text { d.m.s }=\mathrm{q} \cdot \sqrt{ } \mathrm{Q} \cdot \mathrm{M} \cdot \mathrm{R} / \mathrm{n}^{0}
$$

(Equação 1)

Onde $\mathrm{n}^{0}$ é o número de repetições e Q.M.R. é o quadrado mínimo residual obtido no cálculo da ANOVA (tabela 8). Para a obtenção do valor de q foi necessário consultar a tabela do teste de Tukey com $\alpha=0,05$ e K $=3$ (três Formações: Tb-Km-Kss) e o grau de 
liberdade do QMR (tabela 7). O q tabelado encontrado foi igual a 3,36 enquanto o valor do $\mathrm{QMR}=1494,072$ e o numero de repetições foi de 22 resultados. Assim o d.m.s = $3,36 \sqrt{1494,072 / 22}$, ou seja, $\mathrm{dms}=27,69$. Finalmente, comparou-se a diferença entre as médias dos valores de sódio nas Formações Barreiras (Tb), Marizal (Km) e São Sebastião (Kss) com o valor do d.m.s. Quando o valor da diferença entre as médias é maior ou igual ao valor da d.m.s significa que a diferença entre duas médias é significativa $\left(\mu_{\mathrm{a}} \neq \mu_{\mathrm{b}}\right)$. No caso da diferença for menor ou igual ao d.m.s significa que as médias são iguais ou significativas $\left(\mu_{\mathrm{a}=} \mu_{\mathrm{b}}\right)$. No caso do elemento sódio, os resultados mostraram que existe somente diferença entre as médias da Formação Barreiras com a Formação São Sebastião, para as demais são iguais (Tabela 8).

Tabela 8 - Estudo comparativo entre as médias e a diferença mínima significativa de sódio para as Formações Barreiras, Marizal e São Sebastião

Table 8 - Comparative study between the average and the minimum significant difference of sodium from Barreiras, Marizal and São Sebastião Formations

\begin{tabular}{|c|c|c|c|c|}
\hline $\begin{array}{c}\text { Comparações } \\
\text { entre Formações }\end{array}$ & $\begin{array}{c}\text { Diferença entre as mé- } \\
\text { dias (A) }\end{array}$ & $\begin{array}{l}\text { d.m.s } \\
\text { ( B) }\end{array}$ & $\begin{array}{c}\text { Comparação entre } \\
\text { A e B }\end{array}$ & Resultado \\
\hline $\begin{array}{c}\text { Barreiras / } \\
\text { Marizal }\end{array}$ & $\begin{array}{c}\mathrm{Tb}-\mathrm{Km}= \\
18,59\end{array}$ & 27,69 & $\mathrm{~A} \leq \mathrm{B}$ & $\mu \mathrm{Tb}=\mu \mathrm{Km}$ \\
\hline $\begin{array}{l}\text { Barreiras/ } \\
\text { S.Sebastião }\end{array}$ & $\begin{array}{c}\mathrm{Tb}-\mathrm{Kss}= \\
28,06\end{array}$ & 27,69 & $A \geq B$ & $\mu \mathrm{Tb} \neq \mu \mathrm{Kss}$ \\
\hline $\begin{array}{c}\text { Marizal/ } \\
\text { S.Sebastião }\end{array}$ & $\begin{array}{c}\mathrm{Km}-\mathrm{Kss}= \\
9,47\end{array}$ & 27,69 & $\mathrm{~A} \leq \mathrm{B}$ & $\mu \mathrm{Km}=\mu \mathrm{Kss}$ \\
\hline
\end{tabular}

Para o elemento potássio utilizou-se a mesma metodologia do sódio, ou seja, iniciou-se pelo cálculo da diferença mínima significativa (d.m.s) e os passos seguintes foram exatamente os mesmos.

Os resultados mostraram que no caso do potássio, existem diferenças entre as médias das Formações Barreiras e Marizal e Marizal com a Formação São Sebastião. A única igualdade foi entre as Formações Barreiras e São Sebastião (Tabela 9).

Tabela 9 - Estudo comparativo entre as médias e as diferenças mínimas significativas de potássio para as Formações Barreiras, Marizal e São Sebastião

Table 9 - Comparative study between the average and the minimum significant differences potassium of the Barreiras, Marizal and São Sebastião Formations

\begin{tabular}{ccccc}
$\begin{array}{c}\text { Comparações entre Forma- } \\
\text { ções }\end{array}$ & $\begin{array}{c}\text { Diferença entre } \\
\text { as médias }(\mathbf{A})\end{array}$ & $\begin{array}{c}\text { d.m.s } \\
(\mathbf{B})\end{array}$ & $\begin{array}{c}\text { Comparação entre } \\
\text { A e B }\end{array}$ & Resultado \\
\hline Barreiras/Marizal & $\begin{array}{c}\mathrm{Tb}-\mathrm{Km}= \\
3,77\end{array}$ & 3,73 & $\mathrm{~A} \geq \mathrm{B}$ & $\mu \mathrm{Tb} \neq \mu \mathrm{Km}$ \\
Barreiras/S.Sebastião & $\begin{array}{c}\mathrm{Tb}-\mathrm{Kss}= \\
0,66\end{array}$ & 3,73 & $\mathrm{~A} \leq \mathrm{B}$ & $\mu \mathrm{Tb}=\mu \mathrm{Kss}$ \\
Marizal/S.Sebastião & $\begin{array}{c}\mathrm{Km}-\mathrm{Kss}= \\
4,43\end{array}$ & 3,73 & $\mathrm{~A} \geq \mathrm{B}$ & $\mu \mathrm{Km} \neq \mu \mathrm{Kss}$ \\
\hline
\end{tabular}

Para identificar se houve um processo de troca iônica com os níveis argilosos existentes nas três Formações estudadas utilizouse o modelo de Schoeller (1962), in Fenzl (1986).

Numa água que inicialmente teve uma composição iônica equilibrada do tipo alcali- no-terroso $\left(\mathrm{Ca}^{++}+\mathrm{Mg}^{++}=\mathrm{SO}_{4}^{--}+\mathrm{NO}_{3}^{-}\right) \mathrm{e}$ que sofreu uma troca com os íons alcalinos do aquífero, o índice utilizado é: $\mathrm{I}=\mathrm{Cl}^{-}-$ $\left(\mathrm{Na}^{+}+\mathrm{K}^{+}\right) / \mathrm{SO}_{4}^{--}+\mathrm{HCO}_{3}^{-}+\mathrm{NO}_{3}^{-}$) (valores em $\left.\mathrm{mEq} \cdot \mathrm{L}^{-1}\right)$. Se o valor encontrado for negativo é um forte sinal de que houve troca iônica entre os níveis argilosos com a água sub- 
terrânea.

Os cálculos efetuados mostraram o valor de 0,618 para a Formação Barreiras, 0,601 para a Formação Marizal e - 0,614 para a Formação São Sebastião. O valor negativo da Formação São Sebastião indica que houve troca iônica entre os níveis argilosos com a água subterrânea, provavelmente devido aos diversos níveis de material argiloso (folhelhos) existente nessa Formação, principalmente no Membro Passagem Teixeira

Para detectar processos de adsorção simples se usa a relação:

$\mathrm{I}=\left(\mathrm{Ca}^{++}+\mathrm{Mg}^{++}\right)-\mathrm{HCO}_{3}^{-}(\mathrm{em}$ $\left.\mathrm{mEq} \cdot \mathrm{L}^{-1}\right)$ (FENZL, 1986). Equação 2

Se I for menor que zero indica que a deficiência em ions $\mathrm{Ca}^{++}$provém em geral da troca do $\mathrm{Ca}^{++}$por $\mathrm{Na}^{++}$. Nesse caso a água será do tipo $\mathrm{Na}^{+}-\mathrm{HCO}_{3}^{-}$frequentes em águas costeiras que antigamente estavam em contatos com águas marinhas, onde as argilas e outros trocadores estão ocupados por excesso de íons $\mathrm{Na}+$

Os cálculos efetuados com os valores de $\mathrm{Ca}^{++}, \mathrm{Mg}^{++}$e $\mathrm{HCO}_{3}{ }^{-}$mostraram que $6,3 \%$ dos poços situados na Formações Barreiras, $13,6 \%$ na Formação Marizal e 25,9\% na Formação São Sebastião, apresentaram valores de I inferiores a zero, confirmando uma maior frequência de troca de $\mathrm{Ca}^{++}$por $\mathrm{Na}^{+}$na Formação São Sebastião.

A matriz de correlação (Sperman) mostrou uma forte associação entre o sódio e o bicarbonato $(\mathrm{r}=0,70)$ nas águas da formação São Sebastião o que não ocorreu no Barreiras e Marizal. Ao mesmo tempo, verificou-se uma moderada a forte associação entre o PH e o carbonato $(\mathrm{r}=0,66)$, conforme mostram as tabelas 10,11 e 12 .

Tabela 10 - Matriz de correlação (Spearman) Formação Barreiras ( $n=27 ; \alpha=0,05)$

Table 10 - Correlation matrix ( Spearman ) Barreiras Formation ( $n=27 ; \alpha=0.05)$

\begin{tabular}{ccccc}
\hline & Na & K & HCO3 & pH \\
\hline Na & $\mathbf{1 , 0 0}$ & $\mathbf{0 , 5 7}$ & $\mathbf{0 , 4 6}$ & $\mathbf{0 , 3 9}$ \\
K & $\mathbf{0 , 5 7}$ & $\mathbf{1 , 0 0}$ & $\mathbf{0 , 0 1}$ & $\mathbf{0 , 0 5}$ \\
HCO3 & $\mathbf{0 , 4 6}$ & $\mathbf{0 , 0 1}$ & $\mathbf{1 , 0 0}$ & $\mathbf{0 , 6 6}$ \\
pH & $\mathbf{0 , 3 9}$ & $\mathbf{0 , 0 5}$ & $\mathbf{0 , 6 6}$ & $\mathbf{1 , 0 0}$ \\
\hline
\end{tabular}

Tabela 11 - Matriz de correlação (Spearman) Formação Marizal ( $n=23 ; \alpha=0,05)$

Table 11 - Correlation matrix ( Spearman ) Marizal Formation $(\mathrm{n}=23 ; \alpha=0.05$ )

\begin{tabular}{|c|c|c|c|c|}
\hline & $\mathbf{N a}$ & $\mathbf{K}$ & HCO3 & pH \\
\hline $\mathbf{N a}$ & 1,00 & 0,57 & 0,46 & $\mathbf{0 , 3 9}$ \\
\hline K & $\mathbf{0 , 5 7}$ & 1,00 & $\mathbf{0 , 0 1}$ & 0,05 \\
\hline $\mathrm{HCO3}$ & 0,46 & 0,01 & 1,00 & 0,66 \\
\hline pH & 0,39 & 0,05 & 0,66 & 1,00 \\
\hline
\end{tabular}

Tabela 12 - Matriz de correlação (Spearman) Formação São Sebastião ( $n=27 ; \alpha=0,05$ )

Table 12 - Correlation matrix ( Spearman ) São Sebastião Formation $(n=27 ; \alpha=0.05)$

\begin{tabular}{ccccc}
\hline & Na & K & HCO3 & pH \\
\hline Na & $\mathbf{1 , 0 0}$ & $\mathbf{0 , 4 5}$ & $\mathbf{0 , 7 0}$ & $\mathbf{0 , 2 7}$ \\
K & $\mathbf{0 , 4 5}$ & $\mathbf{1 , 0 0}$ & $\mathbf{0 , 5 1}$ & $\mathbf{0 , 3 3}$ \\
HCO3 & $\mathbf{0 , 7 0}$ & $\mathbf{0 , 5 1}$ & $\mathbf{1 , 0 0}$ & $\mathbf{0 , 6 6}$ \\
pH & $\mathbf{0 , 2 7}$ & $\mathbf{0 , 3 3}$ & $\mathbf{0 , 6 6}$ & $\mathbf{1 , 0 0}$ \\
\hline
\end{tabular}




\section{CONCLUSÕES}

As águas subterrâneas nas três forma ções sedimentares estudadas foram classificadas predominantemente como cloretadassódicas e, secundariamente, como bicarbonatadas-sódicas. Essa última foi verificada principalmente na formação São Sebastião. A relação iônica do tipo $\mathrm{rCl}>\mathrm{rHCO}_{3}>\mathrm{rSO}_{4}$ sugere uma associação com a recarga de águas meteóricas enquanto que a associação $\mathrm{rHCO}_{3}>\mathrm{rCl}>\mathrm{rSO}_{4}$, incidindo mais nas águas da formação São Sebastião sugere uma influência da litologia e águas mais distantes das áreas de recarga. Por constituírem-se aquíferos sotopostos, a análise de variância ANOVA mostrou que não existe diferença significativa entre as variâncias para o cálcio, magnésio, cloreto, bicarbonato, sulfato, ferro total, dureza total e condutividade elétrica entre os três aquíferos, considerando um nível de significância $\alpha=0,05$. Afinal de contas são aquíferos semelhantes constituídos majoritariamente por arenitos, variando ora com mais ora com menos intercalações de folhelhos argilosos. No caso da formação São Sebastião formada em ambiente fluvial com alguns episódios de sedimentação lacustrina e de planície aluvial e deltaica, observa-se uma maior presença de níveis com folhelhos argilosos quando comparados com o Barreiras e o Marizal. Os corpos de folhelhos representam, portanto, depósitos de planície de inundação e/ou de preenchimento de meandros abandonados ou ainda, deposições lacustres de águas rasas.

No presente estudo, os valores de sódio e potássio, mostram uma significativa diferença entre as suas variâncias nos três aquíferos. Através do teste de Tukey constatou-se a existência de diferença entre as formações Barreiras e São Sebastião no que

\section{REFERÊNCIAS}

ABOARRAGE, A. M. Estudo da unidade cronoestratigráfica L-1 (Bacia do Recôncavo - Formação São Sebastião). Rio de Janeiro: Petrobras, RPBA, Arquivo DIREX, 1970. (Relatório $\mathrm{n}^{\circ}$ 1358). tange a presença do sódio. Com relação ao potássio, esse teste mostrou diferenças entre as formações Barreiras e Marizal e, também, entre as formações Marizal e São Sebastião, evidenciando que a diferenciação está na formação Marizal. O cálcio e o magnésio não apresentaram variabilidade entre as três formações. Alguns fatores interferem nessas trocas de bases, tais como, as condições de $\mathrm{pH}$ da água subterrânea, do tipo de argila e outros coloides presentes nessas formações sedimentares, além das concentrações desses elementos, entre outros. Nesse estudo verificou-se que o $\mathrm{HCO}^{-}$está associado ao $\mathrm{pH}$ nos três aquíferos, porém o que chama a atenção é a sua forte associação com o sódio na formação São Sebastião, indicando que a variabilidade do sódio depende fortemente do bicarbonato o que facilitam as trocas catiônicas do tipo $\mathrm{XCa} \leftrightarrow \mathrm{XNa}$ no contato água/rocha.

Na aplicação do modelo de Schoeller (1962) ficou evidenciado que o valor negativo da razão $\mathrm{Cl}^{-}-\left(\mathrm{Na}^{+}+\mathrm{K}^{+}\right) / \mathrm{SO}_{4}{ }^{--}+\mathrm{HCO}_{3}{ }^{-}$ $+\mathrm{NO}_{3}^{-}\left(\mathrm{mEq} \cdot \mathrm{L}^{-1}\right)$ encontrado com os dados da Formação São Sebastião o que seria um forte indicativo de que houve realmente troca iônica nesse aquífero em detrimento dos demais que apresentaram valores positivos.

A relação $\left(\mathrm{Ca}^{++}+\mathrm{Mg}^{++}\right)-\mathrm{HCO}^{-}$ (mEq. $\left.\mathrm{L}^{-1}\right)$ apresentou também um valor menor do que zero o que indica uma deficiência em íons $\mathrm{Ca}^{++}$trocado provavelmente por $\mathrm{Na}^{++}$no contacto água/níveis argilosos do São Sebastião. Nesse caso a água será do tipo $\mathrm{rNa}^{+}-\mathrm{rHCO}_{3}{ }^{-}$(bicarbonatada sódica) típica do aquífero São Sebastião. Provavelmente as argilas e outros trocadores contribuíram com íons $\mathrm{Na}^{+}$para a água durante o processo de troca catiônica. Os estudos sobre as trocas de base podem ser o caminho para se distinguir e diferenciar aquíferos sedimentares.

ALVES, J.E. Aspectos hidrogeoquímicos do ferro total no sistema aquífero São Sebastião na área do Polo Industrial de Camaçarí - Bahia. Trabalho Final de Graduação, Instituto de Geociências da UFBA, Salvador, 2012. $57 \mathrm{f}$ 
ALVES, J.E. Estudo hidrogeoquímico comparativo entre os membros da Formação São Sebastião, Recôncavo Norte - BA. Dissertação (Mestrado em Geologia) - Instituto de Geociências, Universidade Federal da Bahia, Salvador, 2015. $107 \mathrm{f}$.

BAHIA. Companhia de Engenharia Ambiental e Recursos Hídricos da Bahia. Cadastro de Poços Tubulares. Salvador: Centro de Documentação, 2010.

BRASIL. Universidade Federal da Bahia. Estudo da Disponibilidade Hídrica e Projeção de Cenários Futuros nas Bacias Hidrográficas do Recôncavo Norte e Inhambupe e seus Domínios Aquíferos no Estado da Bahia - Relatório Final. Salvador: 2012, Núcleo de Estudos Hidrogeológicos e do Meio Ambiente, Instituto de Geociências - UFBA, Projeto Concluído. 498p.

BRASIL. Companhia de Pesquisa de Recursos Minerais. Sistema de Informações de Água Subterrânea - SIAGAS. Disponível em: <http://www.cprm.gov.br>. Acesso em: 15 jan 2015.

INSTITUTO BRASILEIRO DE GEOGRAFIA E ESTATÍSTICA - IBGE. Levantamento de recursos naturais. v. 24 (Suplemento) Folha SD - 24 Salvador. Potencial dos Recursos Hídricos. Rio de Janeiro. 1999. 236 p.

IBGE. Indicadores sociais municipais: 2000. Disponível em: <http://www.ibge.gov.br>. Acesso em: 20 nov. 2014.

FENZL, Norbert; RAMOS, J. F. Introdução à Hidrogeoquímica. Belém: Universidade Federal do Pará, 1986.

FUNCEME - Fundação Cearense de Meteorologia e Recursos Hídricos. Guia do Usuário para Qualigraf. FUNCEME/PROURB-RH. Fortaleza-Ceará, 2014.
NASCIMENTO, S. A. de M.; ALVES J. E. (2011). Caracterização hidrogeoquímica e Evolução da Água Subterrânea na Área do Polo Industrial de Camaçarí - Bahia. In: Simpósio de Geologia do Nordeste, 24, Aracajú, 2011, Anais..., p. 316.

NASCIMENTO, S. A. de M.; ALVES, J. E. Caracterização hidrogeoquímica e evolução da água subterrânea na área do Polo Industrial de Camaçari - Bahia. Cadernos de Geociências, v. 8, n. $2,2011$.

NASCIMENTO, S.A. de M.; ALVES, J.E. Estudo hidrogeoquímico comparativo entre os aquíferos Barreiras, Marizal e São Sebastião na região do Recôncavo Norte, Estado da Bahia. In: Cadernos de Geociências, v.11, n. 1-2, Nov. 2014.

PIPER, A. M. A Graphic Procedure in the Geochemical Interpretation of Water Anallysis. Transactions American Geophysical Union, Washington, v. 25, p. 911-923, 1944.

SCHOELLER, H. Les eaux souterraines. Paris, Mason, 1962, 642p.

SANTOS, P.R.P.; OLIVEIRA, I.B. Avaliação do Gerenciamento das Águas Subterrâneas da Bacia Hidrográfica do Recôncavo Norte, estado da Bahia, utilizando a concessão da outorga de uso como indicador do nível gestão, In: Simpósio Brasileiro de Recursos Hídricos, 17, Simpósio de Hidráulica e Recursos Hídricos dos Países de Língua Oficial Portuguesa, 8, São Paulo, 2007. Anais...2007

WONNACOTT, R. J.; WONNACOTT, T. H. Fundamentos de Estatistica. Rio de Janeiro: LTC, 1985. 348 p. 